\title{
Kırmızı ve mor sebzelerle hazırlanan kombucha çaylarının kalite özelliklerinin belirlenmesi
}

\section{Determination of quality properties of kombucha teas prepared with red and purple vegetables}

\author{
Gökhan AKARCA ${ }^{1}$ (D) Oktay TOMAR ${ }^{2}$ TD \\ ${ }^{1}$ Afyon Kocatepe Üniversitesi, Mühendislik Fakültesi Gıda Mühendisliği Bölümü, Afyonkarahisar, Türkiye \\ ${ }^{2}$ Kocaeli Üniversitesi, Ziraat ve Doğa Bilimleri Fakültesi, Arslanbey Kampüsü, 41285, Kocaeli, Türkiye \\ Sorumlu yazar (Corresponding author): G. Akarca, e-posta (e-mail): gakarca@aku.edu.tr \\ Yazar(lar) e-posta (Author e-mail): oktaytomar@hotmail.com
}

\section{MAKALE BİLGİSİ}

Alınış tarihi 27 Ocak 2020

Düzeltilme tarihi 09 Nisan 2020

Kabul tarihi 09 Nisan 2020

\section{Anahtar Kelimeler:}

Kombucha

Kırmızı havuç

Kırmızı pancar

Mor lahana

Fermantasyon

\begin{abstract}
öz
Bu çalışmada, kırmızı havuç (Daucus carota L. var. atrorubens Alef.), kırmızı pancar (Beta vulgaris var. cruenta Alef.) ve mor lahana (Brassica oleracea L. var. capitata f. rubra) sebzeleri ile üretilen kombucha çaylarının fiziksel, kimyasal, mikrobiyolojik ve duyusal parametreleri araştıılmıştır. 21 günlük fermantasyon süresince örneklerin; $\mathrm{pH}$, briks, su aktivitesi $\left(\mathrm{a}_{\mathrm{w}}\right)$, viskozite, toplam antioksidan kapasite ve fenolik madde miktarı değerlerinin azaldığı $(P<0.05)$, pelikül ağırlığı (biyokütle ağırlığı) değerinin ise arttığ $\quad(P<0.05)$ belirlenmiștir. Üç haftalık fermantasyon sonunda, en düşük $\mathrm{pH}$ ve su aktivitesi değerleri sırasıyla; 3.1 ve 0.899 ile kırmızı havuçtan üretilen örneklerde, en yüksek briks ve viskozite $(100 \mathrm{rpm})$ değerleri ise; 9.59 ve $79 \mathrm{cP}$ ile kırmızı pancardan üretilen kombucha çay örneklerinde olduğu belirlenmiştir. Fermantasyon süresince toplam aerobik mezofilik bakteri (TAMB) ve maya/küf sayıları ile Lactococcus/Streptococcus türü bakteri sayılarının azaldığı, buna karşın ozmofilik maya, asetik ve laktik asit bakteri sayılarının ise arttığı saptanmıştır $(P<0.05)$. Fermantasyon süresince $a^{*}$ değerlerinin arttığı, buna karşın $L^{*}$ ve $b^{*}$ değerinin ise azaldığı $(P<0.05)$ sonucuna varılmıștır. Duyusal analizler sonucunda ise, tüm duyusal kriterler açısından en çok tercih edilen örneğin 8.85 genel beğeni puanı ile kırmızı pancar, en az tercih edilen örneğin ise; 4.03 genel beğeni puanı ile mor lahana ile üretilen örnekler olduğu belirlenmiştir.
\end{abstract}

\section{ARTICLE INFO}

Received 27 January 2020

Received in revised form 09 April 2020 Accepted 09 April 2020

\section{Keywords:}

Kombucha

Red carrot

Red beet

Purple cabbage

Fermentation

\begin{abstract}
In this study investigated the chemical, microbiological, color and sensory parameters of kombucha teas produced with red carrot (Daucus carota L. var. atrorubens Alef.), red beet (Beta vulgaris var. cruenta Alef.) and purple cabbage (Brassica oleracea $\mathrm{L}$. var. capitata $\mathrm{f}$. rubra). During the 21-day fermentation, it was determined that $\mathrm{pH}$, brix, water activity $\left(\mathrm{a}_{\mathrm{w}}\right)$, viscosity, total antioxidant and phenolic content values decreased $(P<0.05)$ whereas pellicle weight value increased $(P<0.05)$. At the end of the three-week fermentation, the lowest $\mathrm{pH}$ and water activity values were 3.1 and 0.899 , respectively, determined in samples produced from red carrots whereas the highest brix and viscosity values $(100 \mathrm{rpm})$ were found in Kombucha tea samples produced from red beet, as $9.59 \%$ and $79 \mathrm{cp}$, respectively. During the fermentation, total aerobic mesophilic bacteria (TAMB) and yeast / mold and Lactococcus / Streptococcus species bacteria counts decreased, whereas osmophilic yeast, acetic and lactic acid bacteria count increased $(P<0.05)$. It was concluded that a* values increased during fermentation whereas $\mathrm{L}^{*}$ and $\mathrm{b}^{*}$ values decreased $(P<0.05)$. As a result of the sensory analysis, the most preferred sample in terms of all sensory criteria was the tea produced using red beet with 8.85 overall rating score whereas the least preferred sample was the tea sample produced with using cabbage with an overall rating of 4.03 .
\end{abstract}




\section{Giriş}

Kombucha çayı Dünya çapında tüketilen hafif tatlı, hafif asitli, ferahlatıcı ve düşük oranda karbondioksit içeriğine sahip bir içecektir. Kombucha çayı, çay yapraklarından elde edilen infüzyona, bakteri ve mayaların simbiyotik birlikteliğinden oluşan çay mantarı ilave edilerek fermantasyonu ile elde edilmektedir (Chen ve Liu 2000). Çin kökenli olan çay, 2000 yıldan fazla zamandır Asya'da geleneksel olarak tüketilmektedir. Bununla birlikte Rusya, Almanya ve Kuzey Avrupa ülkelerinde de sevilerek içilmektedir (Akarca ve Tomar 2018). Köpüklü elma suyunu andıran hafif asitli, karbonatlı ve tatlı bir tada sahip olan çay ticari kültür karıșımları ya da mevcut kombucha kültürü kullanılarak üretilebilmektedir. Çoğunlukla ev ortamında hazırlanarak tüketilmekte olup, ticari boyutta üretim sınırlıdır (Jayabalan ve ark. 2014). Kombucha; şekerli çayda gelişen, zoogleal yapıda, asetik asit bakterileri ile ozmofilik maya türlerinin simbiyotik gelişmesi sonucunda meydana gelen yapıya verilen ortak addır. Pelikül adı da verilen bu yapıdan Acetobacter xylinum gibi karakteristik bakteri türleri ve Pichia cinsine bağlı olarak çeşitli maya türleri ile Brettanomyces, Zygosaccharomyces, Saccharomyces cinsi mayalar izole edilebilir (Jayabalan ve ark. 2014). Ayrica Gluconacetobacter ve Lactobacillus cinslerine ait bakteriler de izole edilebilmektedir (Trovatti ve ark. 2011). Orijinali siyah çaydan üretilen kombucha çayının tadının yumuşatılması, aromasının farklılaştııılması, fonksiyonellik değerini ve besleyiciliğini zenginleştirmek amacıyla diğer bitkisel materyallerde de (nane, adaçayı, ıhlamur, karadut, kuşburnu, kekik, çilek vb.) üretimi gerçekleşmektedir (Jayabalan ve ark. 2014).

$\mathrm{Bu}$ araştırmada, çeşitli kırmızı ve mor sebzeler (kırmızı havuç, kırmızı pancar ve mor lahana) ile hazırlanan kombucha çaylarının fermantasyon süresi boyunca $(0,7,14$ ve 21 . gün) fiziksel, kimyasal, mikrobiyolojik ve duyusal özelliklerinin belirlenmesi amaçlanmıştır.

\section{Materyal ve Yöntem}

\subsection{Materyal}

Çalışmada kullanılan sebzeler (kırmızı havuç, kırmızı pancar ve mor lahana) Afyonkarahisar/Türkiye ilindeki yerel pazarlardan temin edilerek, gerekli alt tür ve varyete düzeyinde teşhisi Afyon Kocatepe Üniversitesi Fen Edebiyat Fakültesi Biyoloji Bölümü öğretim üyeleri tarafindan yapıldıktan sonra, Afyon Kocatepe Üniversitesi Mühendislik Fakültesi Mikrobiyoloji Laboratuvarı'na getirilmiştir.

\subsection{Kombucha çaylarının hazırlanması}

Kombucha çaylarının üretimi Akarca ve Tomar (2018)'ın belirtilen koşullar modifiye edilerek gerçekleştirilmiştir. Kırmızı havuç (Daucus carota L. var. atrorubens Alef.), kırmızı pancar (Beta vulgaris var. cruenta Alef.) ve mor lahana (Brassica oleracea $\mathrm{L}$. var. capitata f. rubra) numunelerinin önce rende ile küçük parçalara ayrılması sağlanmıştır. Ardından her sebzeden 100 'er g, alınarak, üzerine $1000 \mathrm{ml}$ içme suyu ve $100 \mathrm{~g} \mathrm{l}^{-1}$ oranında sakkaroz ilave edilerek tamamen eriyene kadar karıştırılmıştır. Ardından, $95^{\circ} \mathrm{C}$ 'de $15 \mathrm{dk}$ süre ile 1 sıl işlem uygulanmıştır. Isıl işlemin ardından örnekler $20 \mathrm{dk}$ süreyle demlenmeye bırakılmıştır. Süre bitiminde karışımlar steril süzme kağıdından (Whatman, Grade 54, Diameter $55 \mathrm{~mm}$ ) süzülerek, ağzı kapalı kavanozlar içerisinde $121^{\circ} \mathrm{C}$ de $20 \mathrm{dk}$ süre ile otoklavda (Nüve-OT 90L, Türkiye) sterilize edilmiştir.
Örnekler $25^{\circ} \mathrm{C}$ 'ye kadar soğutulduktan sonra, içlerine daha önceden üretilen siyah kombucha çayının sıvı fazından $150 \mathrm{ml}$ ve pelikül fazından (Bakteri ve Mayaların Simbiyotik Kültürü) ortalama $15 \mathrm{~g} \mathrm{l}^{-1}$ olacak şekilde ilave edilmiş ve 21 gün boyunca $24 \pm 1{ }^{\circ} \mathrm{C}$ 'de karanlık bir ortamda fermantasyona bırakılmıştır.

\subsection{Fiziksel ve kimyasal analizler}

Fermantasyon süresi boyunca haftalık olarak örneklerin $\mathrm{pH}$ değeri Hanna (HI 2215, Almanya) $\mathrm{pH}$ metre ve briks (\% çözünür kuru madde içeriği) el refraktometresi (Atago Refractometer N-1E, Japonya) kullanılarak Budak (2015)'te belirtildiği şekilde ölçülmüştür. Viskozite $(50$ ve $100 \mathrm{rpm})$ (Brookfield, Middleboro, MA, ABD) 2 numaralı spindle kullanılarak oda sıcaklığında (Ryan 2019), mantar ağırlığ hassas terazide (Radwag PS-1000 R2, Polonya), su aktivitesi (aw) su aktivitesi ölçüm cihazında (Novasina, LabTouch, İsviçre), renk değerleri ise kolorimetre (Konika Minolta Krom Metre CR-400) kullanılarak Akarca ve ark. (2015)'e göre ölçülmüştür. Toplam antioksidan kapasite (\% inhibisyon) ve toplam fenolik madde miktarı ( $\mathrm{mg} \mathrm{GAE}^{-1}$ ) analizleri ise DPPH ve Folin-Ciocalteu yöntemlerine göre Bekir ve ark. (2013)'te belirtildiği şekilde yapılmıştır. Toplam antioksidan kapasite (\% inhibisyon) hesaplanması ise aşağıdaki formüle göre yapılmıştır.

$$
\text { \% İnhibisyon: } 100\left(A_{\text {(kör) }}-A_{\text {(örnek) })}\right) / A_{\text {(kör) }}
$$

\section{A: 520 nm'de absorbans değeri.}

\subsection{Mikrobiyolojik analizler}

Kombucha çaylarının mikrobiyolojik analizleri yayma plak metoduna göre yapılmıştır. Buna çay örneklerinden hazırlanan dilüsyonlardan 0.1 'er $\mathrm{ml}$ steril bir otomatik pipet (Research Plus, Eppendorf, Almanya) yardımıyla alınarak uygun besiyerlerine inokule edildikten sonra steril drigalski spatülü (Fıratpen, Türkiye) yardımıyla yüzeye homojen bir şekilde yayılmıştır. Toplam aerobik mezofilik Bakteri (TAMB) sayısı analizi; Plate Count Agar (PCA) (Merck 1.05463, Almanya) ile, $30^{\circ} \mathrm{C}$ aerobik koşullarda $48 / 72$ saat (ISO 2013), Maya/Küf sayıs1 analizi; Rose Bengal Chloramphenicol Agar (Merck 1.00467) ile aerobik koşullarda $22^{\circ} \mathrm{C}^{\prime}$ de $3 / 5$ gün (ISO 2008a), Ozmofilik maya sayısı analizi; DG-18 Agar (Merck 1.04092, Almanya) ile, aerobik koşullarda $30^{\circ} \mathrm{C}$ 'de 5-7 gün (ISO 2008b), laktik asit bakteri sayısı analizi; Man Rogasa and Sharpe (MRS) Agar (Merck 1.10661, Almanya) ile $30^{\circ} \mathrm{C}$ 'de anaerobik koşullarda 24/48 saat (Tomar ve ark. 2018), Lactococcus/Streptococcus türü bakteri sayıs1 analizi; M-17 Agar (Merck, 1.15108, Almanya) ile $30^{\circ} \mathrm{C}$ 'de aerobik koşullarda, 24/48 saat (Halkman 2005) ve asetik asit bakteri sayısı analizi Yeast Extract Calcium Carbonate Glucose (YCG) Agar (Himedia M1182, India) ile $30^{\circ} \mathrm{C}$ 'de aerobik koşullarda 5/10 gün sürede (De Vero ve ark. 2006) yapılmıştır. İnkubasyon sonunda tüm paralellere ait sonuçların ortalamaları alınmış, tespit edilen değer 10 ile çarpılarak örneklerin ml'sinde bulunan mikroorganizma sayıları hesaplanmıştır.

\subsection{Duyusal analiz}

Örneklerin duyusal değerlendirilmesi, fermantasyonun 21. gününde Akarca ve ark. (2015)'de belirtilen duyusal test parametreleri modifiye edilerek oluşturulan puan kartları kullanılarak yapılmıştır. Analizler, Afyon Kocatepe Üniversitesi Gıda Mühendisliği Bölüm öğretim üyeleri ile doktora 
öğrencilerinden oluşan yirmi panelist tarafından gerçekleştirilmiştir. Numuneler tat, yapı, görünüş, koku ve genel beğeni alanlarında 1-10 arasında hedonik skala ile değerlendirilmiştir.

\subsection{Istatistiksel analizler}

Araştırmada analizler çift tekerrür ve çift paralel olarak yapılmış olup, istatistiksel sonuçlar SPSS V 23.0.0.0 istatistik programı kullanılarak hesaplanmıştır.

\section{Bulgular ve Tartışma}

Üç haftalık fermantasyon süresince örneklerin tamamında $\mathrm{pH}$ değeri azalmıştır $(P<0.05$; Çizelge 1$) . \mathrm{pH}$ değeri üzerine, örnek çeşidi, depolama süresi ve örnek çeşidi x depolama süresi $(P<0.0001)$ etkileşiminin çok önemli düzeyde etkisinin olduğu belirlenmiştir (Çizelge 2). Fermantasyon sonunda, en düşük $\mathrm{pH}$ değerleri 3.10 ile kırmızı pancar, en yüksek ise; 4.15 ile mor lahana örneklerinde olduğu tespit edilmiştir $(P<0.05$; Çizelge 1). Mor lahana örneğinin $\mathrm{pH}$ değerinin daha yüksek kalmasının, bileşiminde bulunan fermente olabilir şekerler miktarının diğer iki sebzeye kıyasla daha az olmasından kaynaklandığ 1 düşünülmektedir.

Alejandra ve ark. (2019) araştırmasında kombucha çaylarının fermentasyon süresi boyunca $\mathrm{pH}$ değerlerinin azaldığını belirlemişlerdir. Araştırmada elde edilen sonuçlar bu çalışma bulgularıyla ile paraleldir. Fermentasyon süresince $\mathrm{pH}$ değerinde meydana gelen azalma; başta asetik ve laktik asit olmak üzere fermentasyon süresince oluşan organik asitlerin konsantrasyonundaki artıştan kaynaklanmaktadır (Chen ve Liu 2000).

Bütün örneklerin pelikül ağırlığı fermentasyon sonucunda artmıştır $(P<0.05$; Çizelge 1). Pelikül miktarının artışı üzerinde, örnek çeşidi, fermentasyon süresi ve örnek çeşidi $x$ fermentasyon süresi $(P<0.0001)$ interaksiyonunun çok yüksek yüzeyde etkisinin olduğu belirlenmiştir (Çizelge 2). Fermentasyon süresince en fazla artışın $22.84 \mathrm{~g}$ ile kırmızı pancar örneğinde, en az artış ise $2.04 \mathrm{~g}$ ile mor lahana örneğinde olduğu belirlenmiştir. Pelikül miktarında meydana gelen artışın fermentasyon süresince gelişen, başta ekstra polisakkarit sentezleyen asetik asit bakterilerin gelişmesinden kaynaklandığ 1 düşünülmektedir. Mor lahana örneğinde pelikül miktarının diğer iki sebzeye kıyasla çok düşük oranda artış göstermesinin bu sebzede fermente olabilir şeker miktarının çok daha az olmasından kaynaklandığı düşünülmektedir. Benzer şekilde Susilowati ve ark. (2017) çalışmalarında fermentasyon süresince pelikül biyokütlesinin ağırlığının artış gösterdiğini bildirmişlerdir.

Fermentasyon süresince tüm örneklerin briks değerlerinde azalış gözlenmiştir $(P<0.05)$. Fermentasyon süresi boyunca meydana gelen en fazla azalmanın mor lahana örneğinde (\%5.44) olduğu tespit edilmiştir $(P<0.05$; Çizelge 1$)$. Briks değeri üzerinde örnek çeşidi, fermentasyon süresi ve örnek çeşidi $\mathrm{x}$ fermentasyon süresinin çok anlamı olduğu $(P<0.0001)$ tespit edilmiştir (Çizelge 2).

Abuduaibifu ve Tamer (2019) yaptıkları çalışmalarında kombucha çaylarının briks değerlerinin fermentasyon süresince azalış gösterdiği bildirmişlerdir. Araştırmacılar tarafından tespit edilen değerler ile araştırma sonuçlarımız paralellik göstermektedir. Briks değerindeki azalış, fermentasyon sırasında mayaların sakkarozu, glikoz ve fruktoza hidrolize etmesi ve asetik asit bakterilerinin de glikoz ve fruktozu glikoliz yoluyla etanole dönüştürmesinden kaynaklanmıştır.
Kombucha çay örneklerinin su aktivitesi $\left(\mathrm{a}_{\mathrm{w}}\right)$ değerleri fermentasyon süresince azalış göstermiştir $(P<0.05$; Çizelge 1$)$. Fermentasyon sonunda en düşük su aktivitesi değeri 0.899 ile kırmızı havuç örneğinde, en yüksek su aktivitesi değeri ise 0.942 ile mor lahana örneğinde olduğu tespit edilmiştir. Su aktivitesi değerlerinde meydana gelen azalmanın mikroorganizma gelişmesine bağlı oluşan metabolit varlığının artışı ile ortamdaki serbest su miktarının azalmasına bağlı olduğu düşünülmektedir.

Örneklerin tamamında iki ayrı hızda (50 ve $100 \mathrm{rpm})$ ölçülen viskozite değerleri fermentasyon süresi boyunca azalmıştır $(P<0.05$; Çizelge 1$)$. Ayrıca her iki hızda da viskozite değeri üzerinde örnek çeşidi ve fermentasyon süresinin $(P<0.0001)$ çok fazla anlamlı, $100 \mathrm{rpm}$ hızda yapılan ölçümlerde ise örnek çeşidi $\mathrm{x}$ fermentasyon süresi etkileşiminin anlamlı $(P<0.05)$ olduğu belirlenmiştir (Çizelge 2). Fermentasyon süresi boyunca en fazla azalmanın (her iki hızda yapılan ölçümlerde) mor lahana örneğinde (17 ve $21 \mathrm{cP}$ ) olduğu belirlenmiştir (Çizelge 1). Şekerlerin mikroorganizma faaliyeti sonucunda parçalanmasına bağlı olarak oluşan, suda çözünen kuru madde miktarındaki azalmanın, fermentasyon süresince örneklerin viskozite değerlerinin düşmesinde etkili olduğu düşünülmektedir.

Watawana ve ark. (2016) çalışmalarında; hindistan cevizi suyundan yapılan kombucha çayının fermentasyona bağlı olarak viskozitesinin arttığını bildirmişlerdir. Çalışmalar arasında tespit edilen bu farklılığın üretim, hammadde ve fermentasyon koșullarındaki farklılıktan kaynaklandığı düşünülmektedir.

Fermentasyon süresi boyunca toplam fenolik madde miktarı ve antioksidan kapasite azalmıştır $(P<0.05$; Çizelge 1$)$. Üç haftalık fermentasyon süresi sonunda en düşük toplam fenolik madde miktarı ve antioksidan kapasite değerleri sırasıyla 49.29 mg GAE $1^{-1}$ ve $\% 33.77$ olarak mor lahana örneklerinde belirlenmiştir $(P<0.05$; Çizelge 1$)$. Toplam fenolik madde miktarı ve antioksidan kapasite üzerinde örnek çeşidi ve fermentasyon süresi etkileşimlerinin $P<0.0001$ düzeyinde anlamlı olduğu tespit edilmiştir (Çizelge 2). Fermentasyon süresince toplam fenolik madde ve antioksidan kapasitedeki azalmalar üzerinde asidik koşullar altında hidroliz, izomerizasyon ve polimerizasyon gibi faktörlerin etkili olduğu düşünülmektedir. Chu ve Chen (2006) ile Y1kmış ve Tuğgüm (2019) çalışmalarında, kombucha çaylarında fermentasyon süresince toplam fenolik madde miktarı ile antioksidan kapasitesi değerlerinin düşüş gösterdiğini tespit etmişlerdir. Araştırmacıların bildirdiği sonuçlar ile yapılan bu çalışmanın bulguları benzerlik göstermektedir.

Örneklerin $L^{*}, a^{*}$ ve $b^{*}$ değerleri üzerinde, örnek çeşidi $(P<0.0001)$, fermentasyon süresi $(P<0.0001)$ ve örnek çeşidi $\mathrm{x}$ fermentasyon süresi $(P<0.0001)$ ( $\mathrm{L}^{*}$ hariç) etkileşimlerinin çok fazla anlamlı olduğu ortaya konulmuştur (Çizelge 2). Fermentasyon süresi boyunca örneklerin tamamının L* değerlerinin azaldığı belirlenmiştir $(P<0.05$; Şekil 1). Fermentasyon süresince en fazla azalma (19.88 değer azalma ile) kırmızı pancar örneğinde, buna karşın en az azalma ise (8.29 değerlik azalma ile) mor lahana örneğinde meydana gelmiştir. 21 günlük fermentasyon boyunca kırmızı pancar örneklerinin $\mathrm{a}^{*}$ değerlerinde azalış gerçekleşmiştir $(P<0.05)$. Mor lahana örneklerinde ise $0 ., 7$. ve 14. günlerde artış gözlemlenirken, 21. günde azalma gerçekleșmiștir $(P<0.05)$. Fermentasyonun son gününde en yüksek $\mathrm{a}^{*}$ değeri kırmızı pancar örneğinde (24.45), buna karşın en düşük değer ise mor lahana örneğinde (16.13) olduğu ortaya konulmuştur $(P<0.05$; Şekil 2). Tüm örneklerin $b^{*}$ değerleri fermentasyon süresi 
Çizelge 1. Örneklerin fiziksel ve kimyasal analiz sonuçları.

Table 1. Physical and chemical analysis results of samples.

\begin{tabular}{|c|c|c|c|c|c|c|c|c|}
\hline Kriter & pH & $\begin{array}{c}\text { Pelikül Ağırlığı } \\
\text { (g) }\end{array}$ & 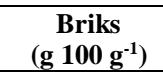 & Su Aktivitesi $\left(\mathbf{a}_{w}\right)$ & $\begin{array}{c}\begin{array}{c}\text { Viskozite } 50 \text { rpm } \\
\text { (cP) }\end{array} \\
\end{array}$ & $\begin{array}{c}\begin{array}{c}\text { Viskozite } 100 \text { rpm } \\
(\mathrm{cP})\end{array} \\
\end{array}$ & $\begin{array}{c}\text { Toplam Fenolik Madde } \\
\left(\text { mg GAE }^{-1}\right)\end{array}$ & $\begin{array}{c}\begin{array}{c}\text { Toplam Antioksidan Kapasite } \\
(\% \text { İnhibisyon) }\end{array} \\
\end{array}$ \\
\hline \multicolumn{9}{|c|}{ (c) } \\
\hline $\mathrm{KH}$ & $3.82 \pm 0.53^{\mathrm{c}}$ & $24.18 \pm 7.32^{\mathrm{b}}$ & $10.36 \pm 1.66^{\mathrm{b}}$ & $0.919 \pm 0.01$ & $57.19 \pm 4.16^{\mathrm{b}}$ & $59.19 \pm 6.01^{\mathrm{b}}$ & $206.12 \pm 24.24^{\mathrm{b}}$ & $67.02 \pm 6.73^{\mathrm{b}}$ \\
\hline KP & $4.21 \pm 0.32^{\mathrm{b}}$ & $28.66 \pm 9.19^{\mathrm{a}}$ & $11.59 \pm 1.42^{\mathrm{a}}$ & $0.935 \pm 0.01$ & $72.50 \pm 4.00^{\mathrm{a}}$ & $85.50 \pm 5.55^{\mathrm{a}}$ & $241.19 \pm 25.64^{\mathrm{a}}$ & $85.73 \pm 8.69^{\mathrm{a}}$ \\
\hline ML & $4.38 \pm 0.23^{\mathrm{a}}$ & $16.90 \pm 3.90^{\mathrm{c}}$ & $8.91 \pm 2.12^{\mathrm{c}}$ & $0.833 \pm 0.07$ & $42.38 \pm 7.05^{\mathrm{c}}$ & $41.63 \pm 8.80^{\mathrm{c}}$ & $70.23 \pm 21.31^{\mathrm{c}}$ & $42.39 \pm 7.67^{\mathrm{c}}$ \\
\hline P Value & $<0.0001$ & $<0.0001$ & $<0.0001$ & 0.547 & $<0.0001$ & $<0.0001$ & $<0.0001$ & $<0.0001$ \\
\hline \multicolumn{9}{|c|}{$\begin{array}{c}\text { Fermentasyon } \\
\text { Zamanı (FZ) }\end{array}$} \\
\hline 0 & $4.55 \pm 0.10^{\mathrm{a}}$ & $16.69 \pm 4.30^{\mathrm{d}}$ & $12.36 \pm 0.75^{\mathrm{a}}$ & $0.947 \pm 0.01$ & $63.50 \pm 12.53^{\mathrm{a}}$ & $70.67 \pm 18.59^{\mathrm{a}}$ & $201.85 \pm 80.67^{\mathrm{a}}$ & $73.90 \pm 19.14^{\mathrm{a}}$ \\
\hline 7 & $4.37 \pm 0.21^{\mathrm{b}}$ & $19.74 \pm 5.80^{c}$ & $11.01 \pm 1.13^{\mathrm{b}}$ & $0.941 \pm 0.01$ & $59.08 \pm 11.88^{\mathrm{b}}$ & $64.67 \pm 18.17^{\mathrm{b}}$ & $180.27 \pm 82.93^{b}$ & $68.69 \pm 20.62^{b}$ \\
\hline 14 & $4.04 \pm 0.20^{\mathrm{c}}$ & $26.66 \pm 7.53^{\mathrm{b}}$ & $9.82 \pm 1.37^{\mathrm{c}}$ & $0.776 \pm 0.01$ & $55.50 \pm 14.15^{\mathrm{c}}$ & $59.08 \pm 20.90^{c}$ & $164.01 \pm 85.96^{\mathrm{c}}$ & $62.32 \pm 19.74^{c}$ \\
\hline 21 & $3.63 \pm 0.43^{\mathrm{d}}$ & $29.88 \pm 9.67^{\mathrm{a}}$ & $7.96 \pm 1.57^{\mathrm{d}}$ & $0.920 \pm 0.01$ & $51.33 \pm 15.73^{\mathrm{d}}$ & $54.00 \pm 21.55^{\mathrm{d}}$ & $143.93 \pm 74.31^{\mathrm{d}}$ & $55.26 \pm 18.43^{\mathrm{d}}$ \\
\hline P Value & $<0.0001$ & $<0.0001$ & $<0.0001$ & 0.409 & $<0.0001$ & $<0.0001$ & $<0.0001$ & $<0.0001$ \\
\hline \multicolumn{9}{|l|}{ Ö x FZ } \\
\hline $\mathrm{KH} \times 0$ & $4.54 \pm 0.01^{\mathrm{b}}$ & $17.96 \pm 1.20^{\mathrm{ef}}$ & $12.35 \pm 0.35^{\mathrm{b}}$ & $0.933 \pm 0.001^{\mathrm{fg}}$ & $62.00 \pm 2.83^{\mathrm{c}}$ & $67.00 \pm 1.41^{\mathrm{c}}$ & $237.03 \pm 6.32^{b}$ & $74.48 \pm 3.82^{\mathrm{c}}$ \\
\hline $\mathrm{KP} \times 0$ & $4.45 \pm 0.03^{\mathrm{c}}$ & $16.18 \pm 0.11^{\text {ef }}$ & $13.18 \pm 0.04^{\mathrm{a}}$ & $0.946 \pm 0.001^{\mathrm{cd}}$ & $78.00 \pm 2.82^{\mathrm{a}}$ & $93.00 \pm 1.41^{\mathrm{a}}$ & $268.97 \pm 7.71^{\mathrm{a}}$ & $94.81 \pm 2.96^{\mathrm{a}}$ \\
\hline ML x 0 & $4.66 \pm 0.01^{\mathrm{a}}$ & $15.96 \pm 0.28^{\mathrm{g}}$ & $11.54 \pm 0.15^{\mathrm{c}}$ & $0.960 \pm 0.002^{\mathrm{a}}$ & $50.50 \pm 2.12^{\mathrm{f}}$ & $52.00 \pm 1.77^{\mathrm{f}}$ & $99.54 \pm 4.51^{\mathrm{f}}$ & $52.41 \pm 2.20^{\mathrm{e}}$ \\
\hline $\mathrm{KH} \times 7$ & $4.43 \pm 0.02^{\mathrm{c}}$ & $17.04 \pm 0.24^{\mathrm{ef}}$ & $11.11 \pm 0.03^{\mathrm{d}}$ & $0.928 \pm 0.003^{\mathrm{g}}$ & $58.75 \pm 1.06^{\mathrm{cd}}$ & $61.00 \pm 1.41^{\mathrm{d}}$ & $214.25 \pm 14.01^{\mathrm{c}}$ & $70.23 \pm 1.48^{\mathrm{cd}}$ \\
\hline $\mathrm{KP} \times 7$ & $4.11 \pm 0.01^{\mathrm{e}}$ & $25.90 \pm 0.23^{\mathrm{d}}$ & $12.22 \pm 0.04^{\mathrm{b}}$ & $0.938 \pm 0.004^{\mathrm{ef}}$ & $72.50 \pm 0.71^{\mathrm{b}}$ & $86.50 \pm 1.41^{\mathrm{b}}$ & $250.90 \pm 3.44^{\mathrm{b}}$ & $90.81 \pm 3.59^{\mathrm{a}}$ \\
\hline ML x 7 & $4.57 \pm 0.01^{\mathrm{b}}$ & $16.29 \pm 0.45^{\mathrm{ef}}$ & $9.71 \pm 0.11^{\mathrm{e}}$ & $0.956 \pm 0.002^{\mathrm{ab}}$ & $46.00 \pm 1.41^{\mathrm{g}}$ & $46.50 \pm 2.12^{\mathrm{g}}$ & $75.65 \pm 2.16^{\mathrm{g}}$ & $45.05 \pm 3.36^{\mathrm{f}}$ \\
\hline KH x 14 & $4.11 \pm 0.02^{\mathrm{e}}$ & $29.09 \pm 0.15^{\mathrm{c}}$ & $9.79 \pm 0.24^{\mathrm{e}}$ & $0.916 \pm 0.002^{\mathrm{h}}$ & $56.00 \pm 1.42^{\text {de }}$ & $56.75 \pm 0.71^{\mathrm{e}}$ & $195.15 \pm 3.30^{\mathrm{d}}$ & $64.91 \pm 2.52^{\mathrm{d}}$ \\
\hline KP x 14 & $3.79 \pm 0.01^{\mathrm{f}}$ & $33.54 \pm 1.54^{\mathrm{b}}$ & $11.36 \pm 0.11^{\mathrm{cd}}$ & $0.935 \pm 0.001^{\mathrm{f}}$ & $71.00 \pm 1.41^{\mathrm{b}}$ & $83.50 \pm 1.41^{\mathrm{b}}$ & $240.43 \pm 8.08^{\mathrm{b}}$ & $82.93 \pm 2.91^{\mathrm{b}}$ \\
\hline ML x 14 & $4.23 \pm 0.01^{\mathrm{d}}$ & $17.35 \pm 1.09^{\text {ef }}$ & $8.31 \pm 0.05^{\mathrm{f}}$ & $0.951 \pm 0.001^{\mathrm{bc}}$ & $39.50 \pm 2.12^{\mathrm{h}}$ & $37.00 \pm 1.41^{\mathrm{h}}$ & $56.45 \pm 10.84^{\mathrm{h}}$ & $39.16 \pm 2.69^{\mathrm{fg}}$ \\
\hline $\mathrm{KH} \times 21$ & $3.76 \pm 0.01^{\mathrm{f}}$ & $32.65 \pm 1.68^{\mathrm{b}}$ & $8.19 \pm 0.06^{\mathrm{f}}$ & $0.899 \pm 0.004^{\mathrm{i}}$ & $52.00 \pm 1.41^{\mathrm{ef}}$ & $52.00 \pm 2.12^{\mathrm{f}}$ & $178.04 \pm 2.01^{\mathrm{e}}$ & $58.48 \pm 2.26^{\mathrm{e}}$ \\
\hline $\mathrm{KP} \times 21$ & $3.10 \pm 0.02^{\mathrm{g}}$ & $39.02 \pm 0.15^{\mathrm{a}}$ & $9.59 \pm 0.09^{\mathrm{e}}$ & $0.919 \pm 0.003^{\mathrm{h}}$ & $68.50 \pm 2.13^{b}$ & $79.00 \pm 1.41^{\mathrm{c}}$ & $204.47 \pm 5.86^{\mathrm{cd}}$ & $74.37 \pm 1.66^{\mathrm{c}}$ \\
\hline ML x 21 & $4.15 \pm 0.01^{\mathrm{e}}$ & $17.99 \pm 0.31^{\mathrm{e}}$ & $6.11 \pm 0.04^{g}$ & $0.942 \pm 0.002^{\mathrm{de}}$ & $33.50 \pm 2.11^{\mathrm{i}}$ & $31.00 \pm 1.41^{\mathrm{i}}$ & $49.29 \pm 1.23^{\mathrm{h}}$ & $33.77 \pm 3.59^{\mathrm{g}}$ \\
\hline P Value & $<0.0001$ & $<0.0001$ & $<0.0001$ & $<0.0001$ & $<0.0001$ & $<0.0001$ & $<0.0001$ & $<0.0001$ \\
\hline
\end{tabular}

KP. Kırmızı Pancar, ML: Mor Lahana, orttstd sapma.

Çizelge 2. Kombucha çay örneklerinin kimyasal analiz sonuçlarına ait varyans analiz sonuçları (F değerleri).

Table 2. Variance analysis results ( $\mathrm{F}$ values) of chemical analysis results of Kombucha tea samples.

\begin{tabular}{|c|c|c|c|c|c|c|c|c|c|c|c|}
\hline Faktör & pH & $\begin{array}{l}\text { Pelikül } \\
\text { Ağırlığı }\end{array}$ & Briks & $\begin{array}{c}\text { Su Aktivitesi } \\
\left(\mathbf{a}_{w}\right)\end{array}$ & $\begin{array}{l}\text { Viskozite } \\
\text { (50 rpm) }\end{array}$ & $\begin{array}{c}\text { Viskozite } \\
(100 \mathrm{rpm})(\mathrm{cP}) \\
\end{array}$ & $\begin{array}{c}\text { Toplam Fenolik Madde } \\
\left(\mathrm{mg} \mathrm{GAE} \mathrm{I}^{-1}\right)\end{array}$ & $\begin{array}{c}\text { Toplam Antioksidan Kapasite } \\
\text { (\% inhibisyon) }\end{array}$ & $\mathbf{L}^{*}$ & a* & $\mathbf{b}^{*}$ \\
\hline Örnek (Ö) & 2272.536 **** & $436.374 * * *$ & $686.272 * * *$ & 1.043 & $499.309^{* * *}$ & $1635.384 * * *$ & $1382.587 * * *$ & $506.756 * * *$ & $383.861 * * *$ & $47.417 * * *$ & $1645.137 * * *$ \\
\hline Zaman (Z) & $1296.157^{* * *}$ & $610.750 * * *$ & $1003.044 * * *$ & 0.634 & $44.259^{* * *}$ & $129.663 * * *$ & $76.720 * * *$ & $52.817 * * *$ & $27.831 * * *$ & $2068.414 * * *$ & $3679.215^{* * *}$ \\
\hline$\ddot{O} \times \mathrm{Z}$ & $124.575^{* * *}$ & $36.375^{* * *}$ & $16.050^{* * *}$ & 1.007 & 2.500 & $3.780 *$ & 1.647 & 0.485 & 2.242 & $99.637 * * *$ & $178.290 * * *$ \\
\hline
\end{tabular}

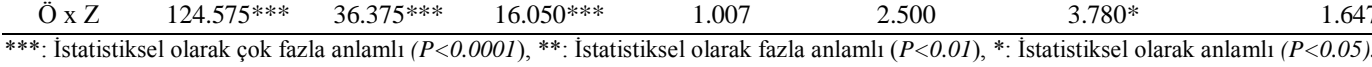




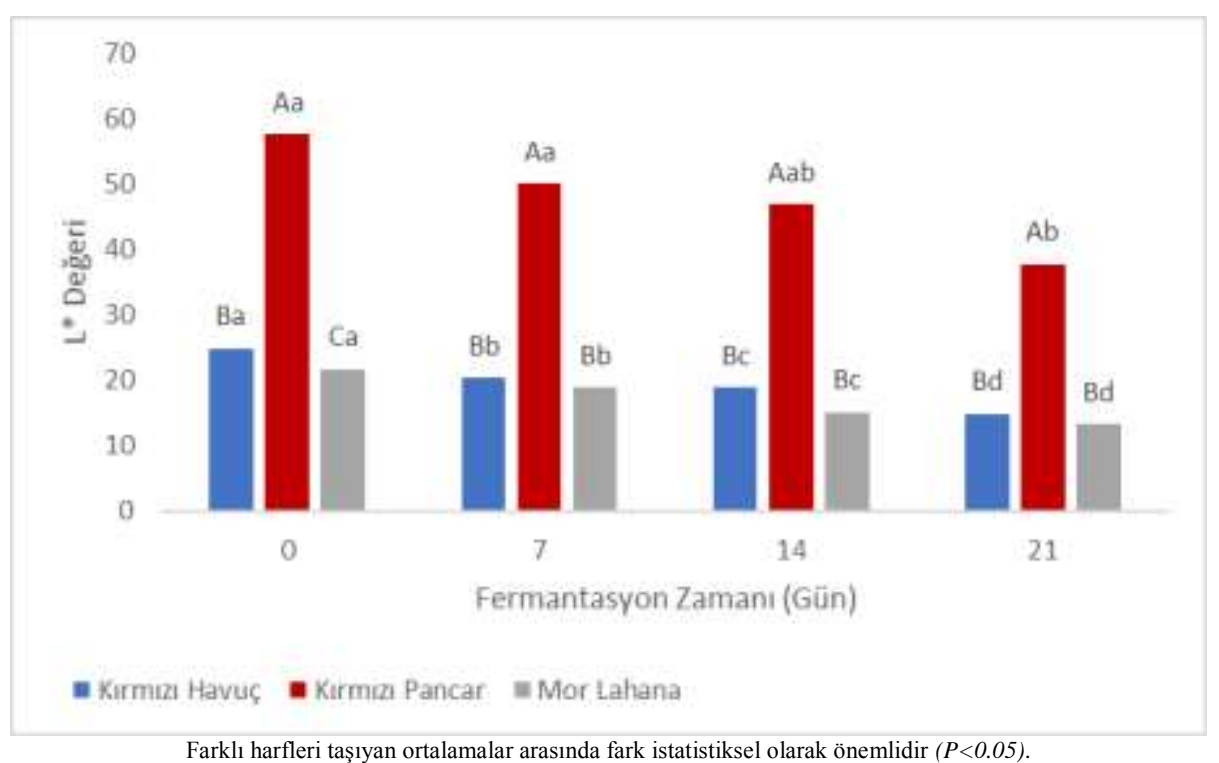

Şekil 1. Fermentasyon süresince örneklerin $L^{*}$ değerindeki değişmeler.

Figure 1. Changes in $L^{*}$ value of samples during fermentation.

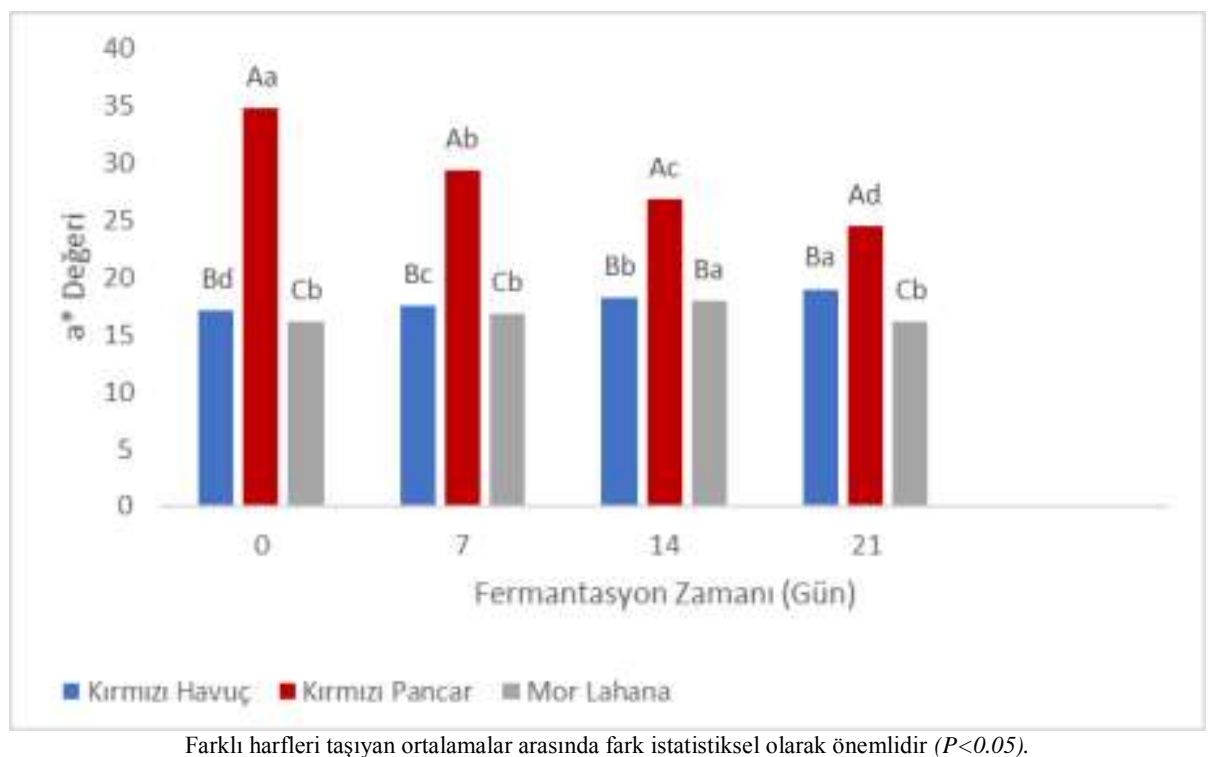

Şekil 2. Fermentasyon süresince örneklerin a* değerindeki değişmeler.

Figure 2. Changes in a* value of samples during fermentation.

boyunca azalmıştır $(P<0.05)$. Fermentasyonun 21. gününde $\mathrm{b}^{*}$ değerleri sırasıyla kırmızı havuç (5.80), kırmızı pancar (5.25) ve mor lahana (5.04) olarak belirlenmiştir ( $P<0.05$; Şekil 3). Fermentasyon süresince en fazla azalışın kırmız havuç örneğinde olduğu tespit edilmiştir. Kombucha çayı örneklerinde, $a^{*}$ değerinin değişimler ile $L^{*}$ ve $b^{*}$ değerlerinin azalmasının nedenlerinin; fermentasyona bağlı olarak pH'ın azalması ve mikroorganizma gelişmesi sonucunda renk pigmentlerinin ve polifenolik bileșenlerin parçalamasından (Watawana ve ark. 2016) kaynaklandığı düşünülmektedir. Abuduaibifu ve Tamer (2019) kombucha çaylarında, renk değerlerinin ( $\left.L^{*}, a^{*}, b^{*}\right) 21$ günlük fermentasyon boyunca artış gösterdiğini bildirmişlerdir. Yapılan çalışma ile bulgularımız arasındaki farklılığın en önemli nedeninin; kullanılan hammaddeler ve özelliklerinin aynı olamamasından kaynaklandığı düşünülmektedir.
Örneklerin tamamında TAMB ve maya/küf sayılarının fermentasyon süresine bağlı olarak azaldığı saptanmıștır $(P<0.05)$. Süre sonunda en düşük TAMB ve maya/küf sayıları sirasiyla 2.11 ve 4.01 Log kob ml ${ }^{-1}$ ile kirmizı pancar örneklerinde olduğu belirlenmiștir (Çizelge 3). Örnekler arasında en az düşüş, mor lahana ile üretilen örneklerde, sırasıyla; 0.11 ve 0.26 Log kob ml ${ }^{-1}$, olarak saptanmıştır. TAMB ve maya/küf sayılarının azalması üzerinde; fermentasyon süresi boyunca asetik ve laktik asit bakteri sayılarındaki artış ile ortamdaki organik asitlerin konsantrasyonlarındaki yükselişin etkili olduğu düşünülmektedir. Y1kmış ve Tuğgüm (2019) araştırma sonuçlarımıza paralel şekilde, tüm kombucha örneklerinin TAMB ve maya/küf sayılarının, Rahmani ve ark. (2019) maya/küf sayılarının fermantasyon süresince azaldığını belirtmişlerdir. 


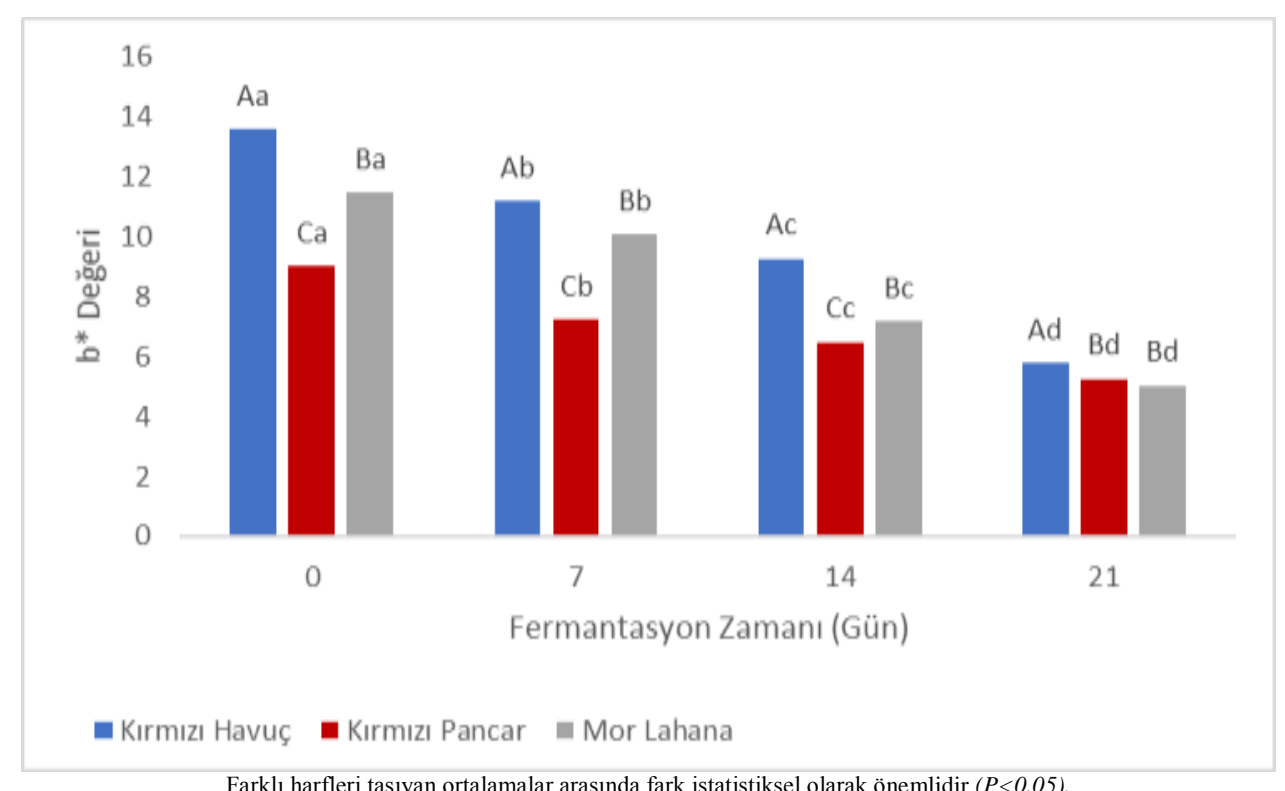

Şekil 3. Fermentasyon süresince örneklerin $b *$ değerindeki değişmeler.

Figure 3. Changes in $b^{*}$ value of samples during fermentation.

Çizelge 3. Örneklerin mikrobiyolojik analiz sonuçları (Log kob $\left.\mathrm{ml}^{-1}\right)$.

Table 3. Microbiological analysis results of samples $\left(\log \mathrm{cfu} \mathrm{ml}^{-1}\right)$.

\begin{tabular}{|c|c|c|c|c|c|c|}
\hline Kriter & $\begin{array}{l}\text { TAMB } \\
\text { Sayısı } \\
\end{array}$ & $\begin{array}{c}\text { Maya/Küf } \\
\text { Sayısı }\end{array}$ & $\begin{array}{c}\text { Ozmofilik } \\
\text { Maya Sayısı }\end{array}$ & $\begin{array}{c}\text { Laktik Asit } \\
\text { Bakterisi Sayısı }\end{array}$ & $\begin{array}{c}\text { Lactococcus/ Streptococcus } \\
\text { Türü Bakteri Sayısı } \\
\end{array}$ & $\begin{array}{c}\text { Asetik Asit } \\
\text { Bakterisi Sayısı }\end{array}$ \\
\hline \multicolumn{7}{|c|}{ Örnek Çeşidi (Ö) } \\
\hline$\overline{\mathrm{KH}}$ & $2.74 \pm 0.33^{\mathrm{a}}$ & $4.89 \pm 0.20^{\mathrm{c}}$ & $2.95 \pm 0.28^{b}$ & $3.98 \pm 0.53^{\mathrm{a}}$ & $3.75 \pm 0.41^{\mathrm{a}}$ & $5.25 \pm 1.35^{\mathrm{b}}$ \\
\hline KP & $2.58 \pm 0.42^{\mathrm{a}}$ & $5.53 \pm 0.37^{\mathrm{a}}$ & $2.57 \pm 0.38^{c}$ & $3.86 \pm 0.77^{\mathrm{a}}$ & $3.80 \pm 0.52^{\mathrm{a}}$ & $5.70 \pm 1.59^{\mathrm{a}}$ \\
\hline ML & $5.68 \pm 0.05^{\mathrm{a}}$ & $5.16 \pm 0.11^{\mathrm{b}}$ & $3.34 \pm 0.25^{\mathrm{a}}$ & $3.45 \pm 0.06^{\mathrm{b}}$ & $3.16 \pm 0.34^{b}$ & $3.92 \pm 0.67^{\mathrm{c}}$ \\
\hline P Value & 0.540 & 0.583 & $\mathrm{P}<0.0001$ & $\mathrm{P}<0.0001$ & $\mathrm{P}<0.0001$ & $\mathrm{P}<0.0001$ \\
\hline \multicolumn{7}{|c|}{$\begin{array}{l}\text { Fermentasyon Zamanı } \\
\text { (FZ) }\end{array}$} \\
\hline 0 & $3.22 \pm 0.14^{\mathrm{a}}$ & $5.14 \pm 0.18^{\mathrm{a}}$ & $2.60 \pm 0.46^{\mathrm{d}}$ & $3.22 \pm 0.19^{\mathrm{d}}$ & $3.16 \pm 0.07^{c}$ & $3.35 \pm 0.22^{\mathrm{d}}$ \\
\hline 7 & $3.01 \pm 0.32^{\mathrm{a}}$ & $4.93 \pm 0.23^{\mathrm{b}}$ & $2.83 \pm 0.33^{c}$ & $3.57 \pm 0.20^{\mathrm{c}}$ & $3.58 \pm 0.19^{b}$ & $4.64 \pm 0.84^{c}$ \\
\hline 14 & $2.74 \pm 0.48^{\mathrm{a}}$ & $4.80 \pm 0.28^{\mathrm{c}}$ & $3.05 \pm 0.32^{\mathrm{b}}$ & $3.92 \pm 0.36^{\mathrm{b}}$ & $3.85 \pm 0.71^{\mathrm{a}}$ & $5.41 \pm 0.99^{\mathrm{b}}$ \\
\hline 21 & $5.70 \pm 0.55^{\mathrm{a}}$ & $4.57 \pm 0.47^{\mathrm{d}}$ & $3.34 \pm 0.31^{\mathrm{a}}$ & $4.33 \pm 0.67^{\mathrm{a}}$ & $3.49 \pm 0.74^{b}$ & $6.41 \pm 1.34^{\mathrm{a}}$ \\
\hline P Value & 0.820 & 0.824 & $\mathrm{P}<0.0001$ & $\mathrm{P}<0.0001$ & $\mathrm{P}<0.0001$ & $\mathrm{P}<0.0001$ \\
\hline \multicolumn{7}{|l|}{ Ö x FZ } \\
\hline $\mathrm{KH} \times 0$ & $3.11 \pm 0.04^{b}$ & $5.19 \pm 0.06^{\mathrm{ab}}$ & $2.62 \pm 0.08^{\mathrm{g}}$ & $3.29 \pm 0.08^{\mathrm{e}}$ & $3.17 \pm 0.08^{\mathrm{fg}}$ & $3.43 \pm 0.15^{\mathrm{h}}$ \\
\hline $\mathrm{KP} \times 0$ & $3.15 \pm 0.03^{\mathrm{b}}$ & $4.93 \pm 0.07^{\mathrm{cd}}$ & $2.07 \pm 0.09^{\mathrm{h}}$ & $2.99 \pm 0.06^{\mathrm{f}}$ & $3.11 \pm 0.09^{\mathrm{gh}}$ & $3.55 \pm 0.16^{\mathrm{h}}$ \\
\hline ML x 0 & $3.40 \pm 0.04^{\mathrm{a}}$ & $5.30 \pm 0.03^{\mathrm{a}}$ & $3.10 \pm 0.09^{\mathrm{cd}}$ & $3.38 \pm 0.05^{\mathrm{e}}$ & $3.21 \pm 0.08^{\mathrm{fg}}$ & $3.10 \pm 0.17^{\mathrm{i}}$ \\
\hline $\mathrm{KH} \times 7$ & $2.96 \pm 0.12^{\mathrm{c}}$ & $4.91 \pm 0.09^{\mathrm{cd}}$ & $2.84 \pm 0.10^{\mathrm{ef}}$ & $3.81 \pm 0.13^{\mathrm{d}}$ & $3.75 \pm 0.08^{\mathrm{de}}$ & $5.15 \pm 0.10^{\mathrm{e}}$ \\
\hline KP $x 7$ & $2.70 \pm 0.02^{\mathrm{d}}$ & $4.69 \pm 0.04^{\mathrm{e}}$ & $2.47 \pm 0.06^{\mathrm{g}}$ & $3.48 \pm 0.04^{\mathrm{e}}$ & $3.63 \pm 0.13^{\mathrm{e}}$ & $5.21 \pm 0.09^{\mathrm{de}}$ \\
\hline ML x 7 & $3.39 \pm 0.03^{\mathrm{a}}$ & $5.19 \pm 0.03^{\mathrm{ab}}$ & $3.19 \pm 0.07^{\mathrm{bcd}}$ & $3.43 \pm 0.06^{\mathrm{e}}$ & $3.37 \pm 0.13^{\mathrm{f}}$ & $3.57 \pm 0.16^{\mathrm{h}}$ \\
\hline KH x 14 & $2.49 \pm 0.06^{\mathrm{e}}$ & $4.81 \pm 0.05^{\mathrm{de}}$ & $3.08 \pm 0.06^{\mathrm{cd}}$ & $4.18 \pm 0.08^{\mathrm{c}}$ & $4.21 \pm 0.11^{\mathrm{ab}}$ & $5.45 \pm 0.10^{\mathrm{d}}$ \\
\hline KP x 14 & $2.38 \pm 0.05^{\mathrm{e}}$ & $4.49 \pm 0.03^{\mathrm{f}}$ & $2.69 \pm 0.11^{\mathrm{fg}}$ & $4.10 \pm 0.19^{c}$ & $4.41 \pm 0.11^{\mathrm{a}}$ & $6.50 \pm 0.13^{\mathrm{c}}$ \\
\hline ML x 14 & $3.35 \pm 0.01^{\mathrm{a}}$ & $5.11 \pm 0.02^{\mathrm{b}}$ & $3.38 \pm 0.08^{\mathrm{b}}$ & $3.48 \pm 0.08^{\mathrm{e}}$ & $2.95 \pm 0.05^{\mathrm{h}}$ & $4.28 \pm 0.06^{\mathrm{g}}$ \\
\hline $\mathrm{KH} \times 21$ & $2.40 \pm 0.08^{\mathrm{e}}$ & $4.69 \pm 0.05^{\mathrm{e}}$ & $3.29 \pm 0.09^{\mathrm{bc}}$ & $4.62 \pm 0.07^{b}$ & $3.89 \pm 0.06^{\mathrm{cd}}$ & $6.99 \pm 0.12^{\mathrm{b}}$ \\
\hline KP x 21 & $2.11 \pm 0.03^{\mathrm{f}}$ & $4.01 \pm 0.13^{\mathrm{g}}$ & $3.03 \pm 0.17^{\mathrm{de}}$ & $4.89 \pm 0.20^{\mathrm{a}}$ & $4.04 \pm 0.13^{\mathrm{bc}}$ & $7.54 \pm 0.16^{\mathrm{a}}$ \\
\hline ML x 21 & $3.29 \pm 0.04^{\mathrm{a}}$ & $5.04 \pm 0.03^{\mathrm{bc}}$ & $3.69 \pm 0.11^{\mathrm{a}}$ & $3.50 \pm 0.02^{\mathrm{e}}$ & $2.55 \pm 0.10^{\mathrm{i}}$ & $4.72 \pm .0 .13^{\mathrm{f}}$ \\
\hline P Value & $<0.0001$ & $<0.0001$ & $<0.0001$ & $<0.0001$ & $<0.0001$ & $<0.0001$ \\
\hline
\end{tabular}

0: Fermantasyon başlangıcı, 7: Fermantasyonun 7. günü, 14: Fermantasyonun 14. günü, 21: Fermantasyonun 21. günü, a-i( $\downarrow)$ Farklı harfleri taşıyan ortalamalar arasında fark istatistiksel olarak önemlidir $(P<0.05)$. KH: Kırmızı Havuç, KP: Kırmızı Pancar, ML: Mor Lahana, ortıstd sapma. 
Örnek çeşidi, fermentasyon süresi ve örnek çeşidi $x$ fermentasyon süresi etkileşimlerinin (ozmofilik maya sayısı hariç) laktik, asetik asit bakteri Lactococcus /Streptococcus türü bakteri ve ozmofilik maya sayıları üzerinde çok fazla anlamlı $(P<0.0001)$ olduğu belirlenmiştir (Çizelge 4). Çalışmada fermentasyon süresi boyunca ozmofilik maya, asetik asit ve laktik asit bakteri sayılarında artış görülmüştür $(P<0.05$; Çizelge 3). Ayed ve ark. (2017) çalışmalarında farklı sicakliklarda fermentasyon süresi boyunca tüm örneklerin ozmofilik maya, asetik asit ve laktik asit bakteri sayılarının arttığını bildirmişlerdir. Çalışmada elde edilen veriler ile araştırmamı bulguları paralellik göstermektedir. Mikroorganizma sayılarında meydana gelen bu artışın, ortamdaki fermente olabilir karbonhidrat miktarının yeterli olması ve ortam koşullarının bu mikroorganizmaların gelişmesine elverişli olmasından kaynaklandığ 1 düşünülmektedir. Lactococcus/Streptococcus türü bakteri sayıları ise; fermentasyonun 14. gününe kadar bir artış göstermesine karşın (mor lahana 7. günden sonra), kalan sürede ise azalmıştır $(P<0.05$; Çizelge 3$)$. Bu azalışın, ortam asitliğinin ve diğer fermentatif mikroorganizmaların sayısının artmasına bağlı olarak Lactococcus/Streptococcus türü bakterilerin gelişmesini baskılamasından kaynaklandığı düşünülmektedir.

Duyusal analiz sonuçları, tüm duyusal kriterler (tat, yapı, görünüş, koku ve genel beğeni) açısından değerlendirildiğinde; en fazla beğenilen örneğin kırmızı pancar, buna karşın en az beğenilen örneğin mor lahanadan üretilen çay örnekleri olduğu ortaya konulmuştur. Kırmızı pancardan üretilen kombucha çay örneğinin tat, yapı, görünüs, koku ve genel beğeni puanları sırasıyla; 8.44, 8.54, 9.46, 7.14, 8.44 olarak, buna karşın kırmızı lahana ile üretilen örneğin ise; $4.05,6.47,7.26,3.58$ ve 4.05 olarak tespit edilmiştir $(P<0.05$; Şekil 4$)$.

\section{Sonuç}

$\mathrm{Bu}$ çalışmada, üç farklı kırmızı ve mor sebze ile üretilen kombucha çay örneklerinin; fiziksel, kimyasal, mikrobiyolojik ve duyusal özellikleri tespit edilmiştir. Araştırma sonucunda özellikle kırmızı pancar ve kırmızı havucun kombucha çayı üretiminde kullanılabileceği, buna karşın mor lahananın kombucha çayı üretimine uygun olmadığ 1 ortaya konulmuştur. Kombucha çayı, vücut tarafindan sindirilen, emilen ve metabolize edilen ve etkilerini hücresel düzeyde uygulayan çok çeşitli biyoaktif bileşenlerin kaynağıdır. Kombucha çayının sağlığa faydalı yönleriyle, son zamanlarda popülerliği artmaktadır. Farklı sebzelerin kombucha çaylarında substrat olarak kullanılmasının lezzet, aroma ve fonksiyonel özellikleri açısından daha fazla tercih edilebileceği düşünülmektedir. Bununla birlikte, Kombucha çayı, sağlığa yararları ve terapötik özelliklere sahip olması nedeniyle gazlı içecek tüketiminin yerine alternatif olabileceği düşünülmektedir.

Sonuçlar, antosiyanin bakımından zengin hammaddelerin kombucha içeceğinin besinsel değerine, fonksiyonel ve duyusal özelliklerine katkıda bulunduğunu göstermiştir. Ancak Kombucha'nın fermantasyon süreci ile biyolojik aktiviteleri arasındaki ilişkiyi değerlendirmek ve fonksiyonel bir içecek olarak kullanımı için kapsamlı bilimsel çalışmalar yapılmalıdır.

Çizelge 4. Kombucha çay örneklerinin mikrobiyolojik analiz sonuçlarına ait varyans analiz sonuçları (F değerleri).

Table 4. Results of variance analysis (F values) of microbiological analysis of Kombucha tea samples.

\begin{tabular}{|c|c|c|c|c|c|c|}
\hline Faktör & ТАМВ & Maya/Küf & Ozmofilik Maya & $\begin{array}{c}\text { Laktik Asit } \\
\text { Bakterisi } \\
\end{array}$ & $\begin{array}{l}\text { Lactococcus/ } \\
\text { Streptococcus }\end{array}$ & $\begin{array}{c}\text { Asetik Asit } \\
\text { Bakterisi }\end{array}$ \\
\hline Çeşit & 0.646 & 0.562 & 127.480 **** & $57.706^{* * *}$ & $175.357 * * *$ & $389.686^{* * * *}$ \\
\hline Depo & 0.307 & 0.301 & $43.417 * * *$ & $126.742 * * *$ & $56.155^{* * *}$ & $564.423 * * *$ \\
\hline Çeşit x Depo & 0.478 & 0.468 & 1.691 & $29.001 * * *$ & $43.630 * * *$ & $35.809 * * *$ \\
\hline
\end{tabular}

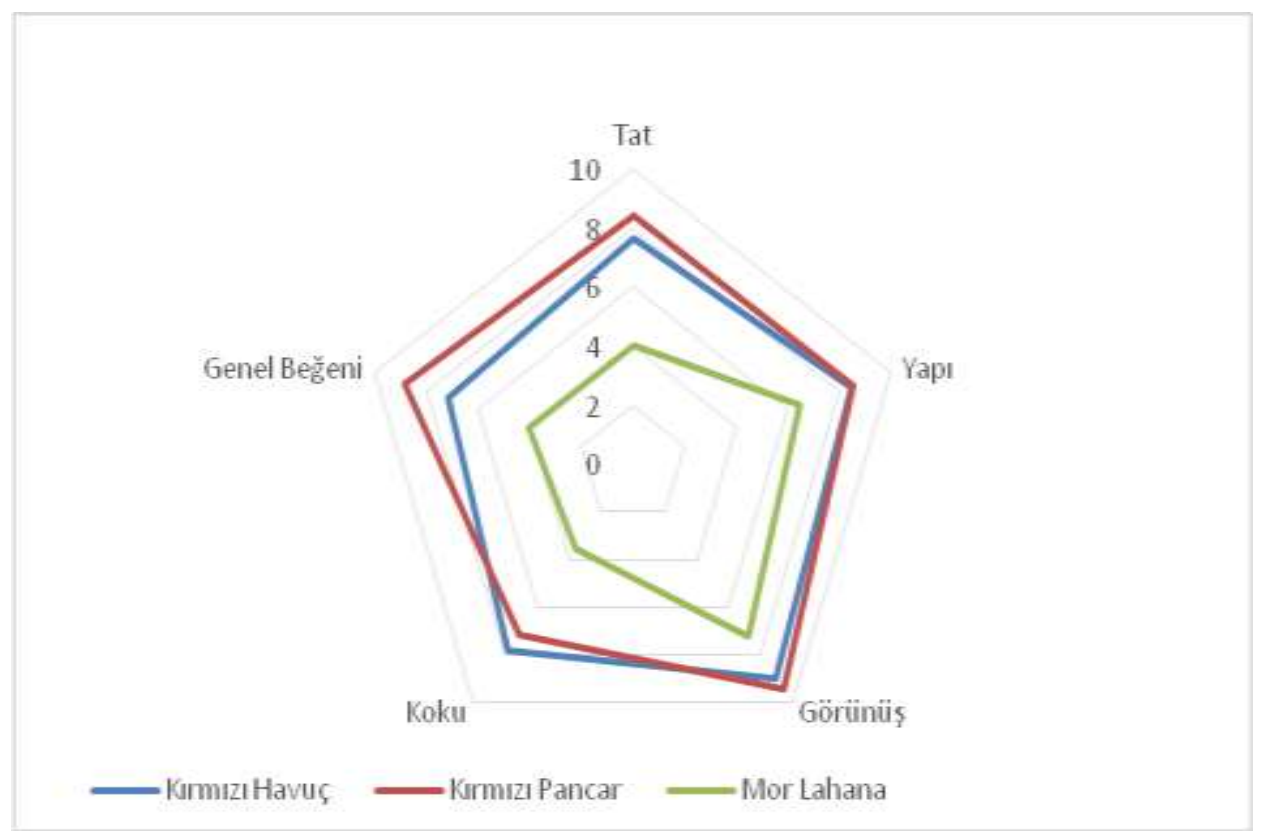

Şekil 4. Kombucha çay örneklerinin duyusal analiz sonuçları.

Figure 4. Sensory analysis results of Kombucha tea samples. 


\section{Kaynaklar}

Abuduaibifu A, Tamer CE (2019) Evaluation of physicochemical and bio accessibility properties of goji berry kombucha. Journal of Food Processing and Preservation 43: 14077.

Akarca G, Tomar O, Gök V (2015) Effect of different packaging methods on the quality of stuffed and sliced mozzarella cheese during storage. Journal of Food Processing and Preservation 39(6): 2912-2918.

Akarca G, Tomar O (2018) Antimicrobial and antioxidative properties of kombucha teas produced with black and green tea. European Journal of Science and Technology 14: 96-101.

Alejandra S, Soto V, Beauforta S, Bouajilaa J, Soucharda JP, Renardc T, Rollanc S, Taillandier P (2019) Impact of fermentation conditions on the production of bioactive compounds with anticancer, anti-inflammatory and antioxidant propertiesin kombucha tea extracts. Brcess Biochestry 83: 44-54.

Ayed L, Ben Abid S, Hamdi M (2017) Development of a beverage from red grape juice fermented with the Kombucha consortium. Annals of Microbiology 67(1): 111-121.

Bekir J, Mars M, Souchard JP, Bouajila J (2013) Assessment of antioxidant, anti-inflammatory, anti-cholinesterase and cytotoxic activities of pomegranate (Punica granatum) leaves. Food and Chemical Toxicology 55: 470-475.

Budak N (2015) Total antioxidant activity and phenolic contents with advanced analytical techniques in the mulberry vinegar formation process. Fruit Science 2(2): 27-31.

Chen C, Liu BY (2000) Changes in major components of tea fungus metabolites during prolonged fermentation. Journal of Applied Microbiology 89: 834-839.

Chu SC, Chen C (2006) Effects of origins and fermentation time on the antioxidant activities of kombucha. Food Chemistry 98: 502-507.

De Vero L, Gala E, Gullo M, Solieri L, Landi S, Giudici P (2006) Application of denaturing gradient gel electrophoresis (DGGE) analysis to evaluate acetic acid bacteria in traditional balsamic vinegar. Food Microbiology 23: 809-813.

Halkman K (2005) Gıda Mikrobiyolojisi Uygulamaları. 1. Baskı. Başak Matbaacılık Ltd. Şti, Ankara.

ISO (2008a) International Standard Organization, ISO 21527-1:2008 Microbiology of food and animal feeding stuffs - Horizontal method for the enumeration of yeasts and moulds - Part 1: Colony count technique in products with water activity greater than 0,95 .
ISO (2008b) International Standard Organization, ISO 21527-2:2008 Microbiology of food and animal feeding stuffs - Horizontal method for the enumeration of yeasts and moulds - Part 2: Colony count technique in products with water activity greater than 0,95 .

ISO (2013) International Standard Organization, 4833-1:2013 Microbiology of the food chain - Horizontal method for the enumeration of micro-organisms - Part 1: Colony count at 30 degrees $C$ by the pour plate technique.

Jayabalan R, Malbasa RV, Loncar ES, Vitas JS, Sathishkumar M (2014) A review on Kombucha tea-microbiology, composition, fermentation, beneficial effects, toxicity, and tea fungus. Comprehensive Reviews in Food Science and Food Safety 13: 538550 .

Rahmani R, Beaufort S, Villarreal-Sotob SA, Taillandier P, Bouajilab J, Debouba M (2019) Kombucha fermentation of African mustard (Brassica tournefortii) leaves: Chemical composition and bioactivity. Food Bioscience 30: 100414.

Ryan J, Hutchings SC, Fang Z, Bandara N, Gamlath S, Ajlouni S, Ranadheera CS (2019) Microbial, physico- chemical and sensory characteristics of mango juice- enriched probiotic dairy drinks. International Journal of Dairy Technology 70: 1-9.

Susilowati A, Iskandar JM, Melanie H, Maryati Y, Lotulung PD (2017) Characteristic of fermented spinach (Amaranthus spp.) polyphenol by kombucha culture for antioxidant compound. AIP Conference Proceedings 183(1): 02018.

Tomar O, Akarca G, Beykaya M, Çağlar A (2018) Some characteristics of Erzincan Tulum cheese produced using different probiotic cultures and packaging material. Journal of the Faculty of Veterinary Medicine Kafkas University 24(5): 647-658.

Trovatti E, Serafim LS, Freire CSR, Silvestre AJD, Neto CP (2011) Gluconacetobacter sacchari: An efficient bacterial cellulose cellfactory. Carbohydrate Polymers 86: 1417-1420.

Watawana MI, Jayawardena N, Gunawardhana CB, Waisundara VY (2016) Enhancement of the antioxidant and starch hydrolase inhibitory activities of king coconut water (Cocos nucifera var. aurantiaca) by fermentation with kombucha 'tea fungus. International Journal of Food Science \& Technology 51(2): 490-498.

Yıkmış S, Tuğgüm S (2019) Evaluation of microbiological, physicochemical and sensorial properties of purple basil kombucha beverage. Turkish Journal of Agriculture-Food Science and Technology 7(9): 1321-1327. 